\title{
Mobile ECMO in COVID-19 patient: case report
}

\author{
Martínez Daniela ${ }^{1,2} \cdot$ Salech Felipe $e^{3,4} \cdot$ Sint Jan Van Nicolette ${ }^{5,6,7} \cdot$ Regueira Tomás $^{5} \cdot$ Villalabeitia Eli6,7 $^{6,7}$ Rufs Jorge $^{7,8}$. \\ Fajardo Christian $^{6,7} \cdot$ Castillo Roberto $^{8} \cdot$ Iñiguez Jose $^{9} \cdot$ Durán Luisa $^{4} \cdot$ Díaz Rodrigo $^{7,8}$ (1)
}

Received: 28 May 2020 / Accepted: 4 September 2020 / Published online: 19 September 2020

(c) The Japanese Society for Artificial Organs 2020

\begin{abstract}
At July 25, 2020, WHO had recorded more than 16.1 million confirmed COVID-19 cases, $1 \%$ of them developed critical illness. These patients can experience rapid progression to profound hypoxemia and severe acute respiratory distress syndrome (ARDS). Some patients, despite receiving lung-protective ventilation and maximal medical therapy, develop refractory hypoxemia, rendering candidates for extracorporeal membrane oxygenation (ECMO) support. Centers with experience in this technique are available only in a few reference hospitals and some patients are too ill to be transferred with conventional mechanical ventilation so they need mobile ECMO (interhospital transport under ECMO). Here we report the first interhospital extracorporeal membrane oxygenation transport of a COVID-19 patient in Chile, showing that it is feasible and safe to transfer a COVID-19 patient under ECMO support if a mobile ECMO program is correctly implemented and the particularities of protective measures are properly taken.
\end{abstract}

Keywords COVID-19 $\cdot$ ECMO $\cdot$ Mobile ECMO $\cdot$ ARDS $\cdot$ Personal protective equipment

Díaz Rodrigo

rdiaz@clc.cl

$1 \quad$ Unidad de Infectología Pediátrica, Hospital San Borja Arriarán, Santiago, Chile

2 Centro de Pacientes Críticos Pediátricos, Clínica Las Condes, Las Condes, Chile

3 Centro de Investigación Clínica Avanzada, Hospital Clínico Universidad de Chile, Independencia, Chile

4 Departamento de Medicina Interna, Clínica Las Condes, Las Condes, Chile

5 Centro de Pacientes Críticos, Clínica Las Condes, Las Condes, Chile

6 Departamento de Cirugía Cardiovascular, Clínica Las Condes, Las Condes, Chile

7 Unidad ECMO, Clínica Las Condes, Las Condes, Chile

8 ECMO Unit, Departamento de Anestesia, Clínica Las Condes, Estoril 450, Las Condes, Santiago, Chile

9 Servicio de Urgencias, Hospital Clínico Magallanes, Punta Arenas, Chile

\section{Introduction}

On December 2019, an outbreak of unexplained pneumonia occurred in Wuhan, China. On January 7, 2020, the causative pathogen was identified as a novel coronavirus, currently named SARS-CoV-2 [1]. The illness caused by this virus-COVID-19-spread swiftly around the globe, and on March 11, 2020, The World Health Organization (WHO) declared COVID-19 as a pandemic [2].

In most patients, the illness produce mild to moderate symptoms but approximately $15 \%$ progress to severe pneumonia, about $1 \%$ of patients experience progression that can quickly progress to profound hypoxemia and/or ARDS [3]. As of June 25, 2020, more than 16.1 million cases of COVID-19 have been confirmed, with 645,752 deaths. Currently, there are no specific approved treatment, nor a vaccine is available, and supportive care remains the cornerstone of management.

ECMO is currently a widely accepted support measure for selected patients with life-threatening respiratory failure that does not respond to maximal support care with mechanical ventilation [4]. However, few centers have this technology available and some patients are too ill to be transferred under conventional transport (mechanical ventilation) to a facility 
that can provide it, meaning that they must be transferred on ECMO support to specialized centers [5].

Safety of healthcare workers is an important aspect of COVID-19 management. Up to $10 \%$ of the reported cases in China and 9\% of those in Italy [6] have been among them. Coronaviruses are believed to be transmitted from person to person via large respiratory droplets, either being inhaled or deposited on mucosal surfaces. Other routes implicated in transmission of coronaviruses include contact with contaminated fomites and inhalation of aerosols produced during aerosol-generating procedures (AGPs). SARS-CoV-2 viral RNA has also been detected on rare occasions in blood specimens but there is no evidence of transmission through contact with blood [7], for AGPs healthcare workers should use airborne-level personal protective equipment (PPE) [7].

Here, we report the first interhospital extracorporeal membrane oxygenation transport of a COVID-19 patient in Chile.

\section{Case report}

51-year-old woman, with a history of hypothyroidism and mild asymptomatic asthma. Thirteen days prior to developing COVID-19 symptoms she arrived healthy from Dominican Republic, back to Punta Arenas, Chile. On March 29, 2020 she was admitted to the Regional Hospital after 2 days of progressive cough and malaise, associated with resting dyspnea. In the emergency department she had sinus tachycardia (heart rate (HR) $120 \mathrm{bpm}$ ), blood pressure $155 / 83 \mathrm{mmHg}$ and polypnea [respiratory rate (RR) $40 \mathrm{bpm}$ ], $50 \% \mathrm{O}_{2}$ pulse oximetry on room air, with poor respiratory mechanics. Consequently, rapid sequence intubation was performed. Laboratory results showed $6.69 \times 10^{9} / \mathrm{L}$ white blood cells, $1.17 \times 10^{9} / \mathrm{L}$ lymphocyte, aspartate aminotransferase $19 \mathrm{U} / \mathrm{L}$, alanine aminotransferase $12 \mathrm{U} / \mathrm{L}$, lactate dehydrogenase $206 \mathrm{U} / \mathrm{L}$; blood urea nitrogen $3.3 \mathrm{mmol} / \mathrm{L}$, creatine kinase $76 \mathrm{mmol} / \mathrm{L}$; procalcitonin $0.11 \mathrm{ng} / \mathrm{mL}$, C-reactive protein $54.86 \mathrm{mg} / \mathrm{L}$; blood gas analysis (ABGs): $\mathrm{pH}$ : 7.41, $\mathrm{pO}_{2} 91 \mathrm{mmHg}, \mathrm{pCO}_{2} 39 \mathrm{mmHg}$, fraction of inspired oxygen $\left(\mathrm{F}_{\mathrm{I}} \mathrm{O}_{2}\right) 70 \%$. Throat swabs of patients were harvested and tested positive for SARS-CoV-2 nucleic acid by the fluorescence quantitative RT-PCR. PCR respiratory panel (FilmArray®), blood and deep airways cultures were negative for others infectious agents.

Chest CT scan showed severe bilateral alveolar condensation with isolated foci of normal parenchyma (Fig. 1). She was managed with on deep sedation (RASS-5), neuromuscular blockade, and recruitment maneuver; hemodynamics was maintained with low dose norepinephrine. Ventilator settings were adjusted to volume-controlled ventilation $6 \mathrm{~mL} / \mathrm{Kg}$ ideal body weight, RR 28 , positive end-expiratory pressure (PEEP) $16 \mathrm{~cm} \mathrm{H}_{2} \mathrm{O}, \mathrm{F}_{\mathrm{i}} \mathrm{O}_{2} 70 \%$, peak inspiratory pressure

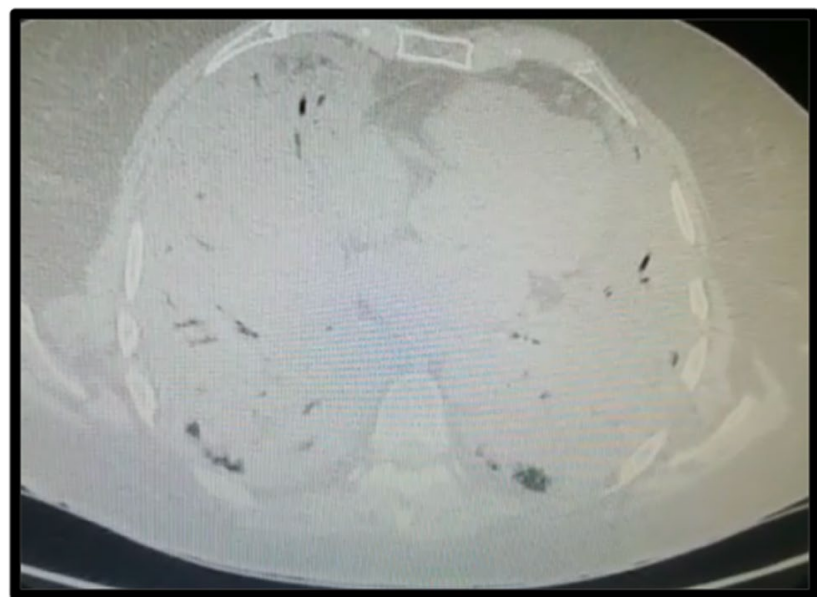

Fig. 1 CT Scan at cannulation time: shows a representative CT slice of the lung obtained $2 \mathrm{~cm}$ above the diaphragm dome. Mechanical ventilator setup: volume controlled ventilation $6 \mathrm{~mL} / \mathrm{Kg}$ ideal body weight, Respiratory Rate 28, PEEP $16 \mathrm{~cm} \mathrm{H}_{2} \mathrm{O}, \mathrm{FiO}_{2} 70 \%$, peak inspiratory pressure $37 \mathrm{~cm} \mathrm{H}_{2} \mathrm{O}$, plateau pressure $27 \mathrm{~cm} \mathrm{H}_{2} \mathrm{O}$

$37 \mathrm{~cm} \mathrm{H} \mathrm{H}_{2} \mathrm{O}$, plateau pressure $27 \mathrm{~cm} \mathrm{H}_{2} \mathrm{O}$, driving pressure $11 \mathrm{~cm} \mathrm{H}_{2} \mathrm{O}$. Static compliance was of $32 \mathrm{~cm} \mathrm{H}_{2} \mathrm{O}$. Control ABGs showed $\mathrm{pH} 7.2 \mathrm{pO}_{2} 100.8 \mathrm{mmHg}\left(\mathrm{PaO}_{2} / \mathrm{F}_{\mathrm{I}} \mathrm{O}_{2}\right.$ ratio 144), $\mathrm{pCO}_{2} 63 \mathrm{mmHg}$. As per protocole, oseltamivir, ceftriaxone, azithromycin and hydroxicloroquine were empirically started. In the next hours $\mathrm{PaO}_{2} / \mathrm{F}_{\mathrm{I}} \mathrm{O}_{2}$ ratio deteriorated to $108 \mathrm{mmHg}$, without improvement after recruitment maneuvers nor the implementation of prone position. Guided per Chilean ARDS's recommendations, transfer to an ECMO unit was requested. Due to patient condition and given distance from the nearest hospital with mobile ECMO capacity (3019 km), she was deemed to need airborne mobile ECMO.

Mobile ECMO team at Clínica Las Condes was deployed, which is composed of a cardiac surgeon, an anesthetist, a perfusionist and an ICU nurse. Since cardiac echoscopy showed no significant left ventricular disfunction, venovenous ECMO was installed. Cannulation was guided by ultrasonography extraction from right femoral vein $(29 \mathrm{Fr})$ and return to patient through right jugular vein (19 Fr). Sweep gas flow 2 LPM; 3200 RPM, 3.4 ECMO flow, titrating parameters until $92 \%$ patient saturation. Rotaflow ${ }^{\circledR}$ centrifugal pump and PLS-i oxygenators (Maquet Cardiopulmonary Hirrlingen ${ }^{\circledR}$, Germany) were used. No complications where reported during cannulation. Ventilatory settings where modified to pressure control $5 \mathrm{~cm} \mathrm{H}_{2} \mathrm{O}$, PEEP $5 \mathrm{~cm}$ $\mathrm{H}_{2} \mathrm{O}$, RR $5 \mathrm{bpm}$, once leaving the hospital, the patient was left in inspiratory apnea at $8 \mathrm{~cm} \mathrm{H}_{2} \mathrm{O}$, and endotracheal tube was clamped to reduce the aerosolization risk. During all these maneuvers the whole team members used PPE according to air transmission; well-fitted N95 respirators, eye protection with visor or goggles, gloves, and long-sleeved impermeable protective gown. 
Airborne transfer lasted $4.5 \mathrm{~h}$. During the flight, the patient remained on deep sedation (RASS-5), neuromuscular blockade, and with her endotracheal tube clamped in apnea. Hemodynamics parameters, pump flow rate and sweep gas flow are shown in Table 1. No complication occurred during the flight (Fig. 2). To minimize the aerolization risk of SARS-CoV-2 through the gas-exit port of the membrane lung we kept a strict control for the detection of plasma leakage signs in the exhaust port of the oxygenator [8]. Whole team members used air-borne transmission adequate PPE. According to the Chilean Ministry of Health's guidelines for the transportation of COVID-19 patient, the crew (pilot and copilot) used droplets and contact sufficient PPE, embarked and disembarked at different time than healthcare personnel and patient; cabin was isolated from the rest of the aircraft and HEPA filters were used in ventilation circuits. After arrival, the cabin was disinfected with isopropyl alcohol and the rest of the aircraft with quaternary ammonium, and disinfection of the room-air was carried out by the filter using an ozone generating device.

On arrival at the referral center (Clínica Las Condes, Santiago, Chile), endotracheal tube clamp was removed, and mechanical ventilation was set to pressure control, support pressure $10 \mathrm{~cm} \mathrm{H}_{2} \mathrm{O}$, RR $10 \mathrm{bpm}$, PEEP $10 \mathrm{~cm}$ $\mathrm{H}_{2} \mathrm{O}, \mathrm{F}_{\mathrm{I}} \mathrm{O}_{2} 30 \%$. ABGs showed $\mathrm{pH} 7.38 \mathrm{pO}_{2} 92.8 \mathrm{mmHg}$, $\mathrm{pCO}_{2} 32 \mathrm{mmHg}$. Physical examination suggested deep vein thrombosis of right inferior limb, which was confirmed with echography, patient was transferred to the operating room, where vascular access was reconfigured to left axillar vein drainage, no significant recirculation nor other complication occurred. Parameters where readjusted to 41 pm RPM 3700 and FGF 3 lpm until ABGs normalized.

Prone position ventilation for $48 \mathrm{~h}$ and ultrafiltration through the circuit to reach negative water balance were implemented. Native lung function progressively improved and decannulation was undertaken on day 6th

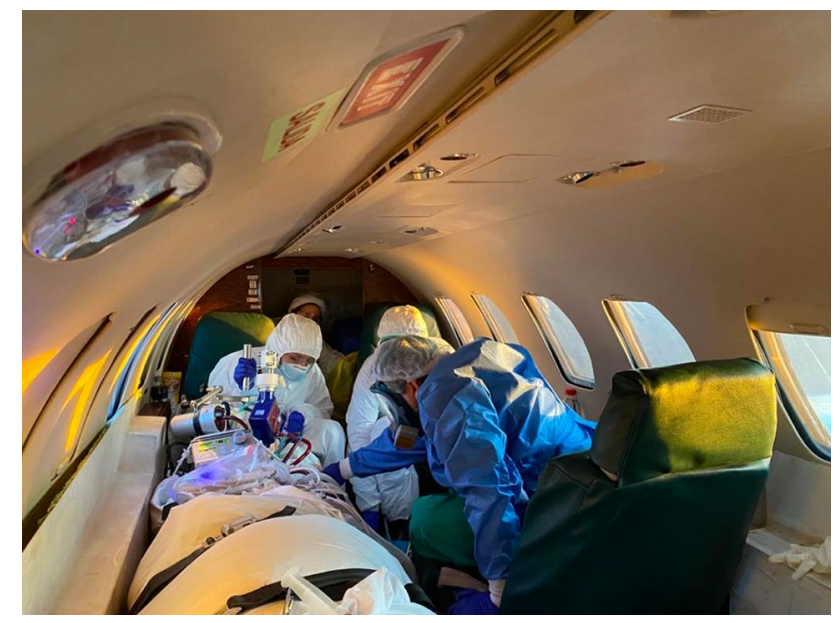

Fig. 2 ECMO air transport: Airborne transfer lasted 4.5 h $(3019$ km distance). During the flight, the patient remained with her endotracheal tube clamped. All the team members, used air-borne transmission adequate PPE

after cannulation. An inferior vena cava filter was installed given the high thrombotic load. Ten days of treatment with hydroxychloroquine were completed, azithromycin was stopped after 4 days due to QT prolongation.

On day 14th after admission, methicillin sensitive Staphylococcus aureus pneumonia was confirmed, cefazolin was started, and a second round of prone positioning was needed (48 h). Considering prolonged invasive mechanical ventilation, tracheostomy was performed on day 24 after admission, with appropriate air- transmission PPE, without incidents. Given adequate clinical and laboratory response, neuromuscular blockade and deep sedation where progressively retired. A multimodal rehabilitation process was implemented, with a good response. Tracheostomy was removed, and the patient was discharged to home in a good general condition.
Table 1 Clinical, ECMO and mechanical ventilator parameters at different times of the transport process

\begin{tabular}{lllll}
\hline & Pre-departure (1) & 1 h flight (2) & 3 h flight (2) & Arrival (3) \\
\hline $\mathrm{HR}(\mathrm{bpm})$ & 110 & 95 & 90 & 96 \\
$\mathrm{SaO} 2(\%)$ & 90 & 96 & 91 & 92 \\
$\mathrm{BP}(\mathrm{mmHg})$ & $99 / 50$ & $101 / 56$ & $109 / 58$ & $120 / 65$ \\
ECMO flow (lt/min) & 3.4 & 3.9 & 4.1 & 4.0 \\
Sweep gas (lt/min) & 2 & 4 & 4 & 4 \\
PEEP (cm $\left.\mathrm{H}_{2} \mathrm{O}\right)$ & 5 & - & - & 10 \\
RR (rpm) & 5 & - & - & 10 \\
Inspiratory pressure $\left(\mathrm{cm} \mathrm{H}_{2} \mathrm{O}\right)$ & 5 & - & - & 10 \\
\hline
\end{tabular}

1-Before air transport, 2 - at 2 different times during the air transport, and 3 -at the arrival to the destination ECMO center 


\section{Discussion}

Here we report the first documented interhospital ECMO transport of a COVID-19 patient showing that it is feasible and safe if a mobile ECMO program is correctly implemented and the particularities of protective measures are properly taken.

ECMO was studied for ARDS treatment in patients with Middle East Respiratory Syndrome Coronavirus (MERS$\mathrm{CoV}$ ), a similar coronavirus disease that emerged in 2012, showing a significant decrease of in-hospital mortality in patients supported by ECMO compared to those managed with conventional therapy [9]. At this time there is little worldwide reported experience regarding ECMO support on COVID-19 patients [10-12], although the WHO's guidance document includes a statement to "consider referral patients with refractory hypoxemia despite lung-protective ventilation in settings with access to expertise in ECMO [13]. Considering that, if ECMO expertise is available, it should be considered into ARDS managing algorithms, including ARDS secondary to viral pneumonia.

The Extracorporeal Life Support Organization (ELSO) reports at July 25, 2020, 1972 confirmed COVID-19 cases have been supported with ECMO, and 55\% of discharged patients are alive (753 out 1365). As treatment for severe respiratory failure with ECMO requires specialized knowledge and training, the number of patients annually supported with ECMO is positively associated with the survival rate [5]. It is also known that hospitalization at a center, where health care professionals are well-trained on respiratory care results in improved outcomes [14]. Therefore, it is recommended that those patients who meet the criteria to be connected to ECMO should be transferred to centers with high experience in this technique [12].

However, few centers have this technology available in situ and some patients are too ill to be transferred under conventional transport (mechanical ventilation) to a facility that can provide it, meaning that they must be transferred on ECMO support to specialized centers [5].

On March 3 2020, the first COVID-19 case was reported in Chile and as on July 25 the Ministry of Health has reported 343,592 COVID-19 confirmed cases nationwide, $1 \%$ of them are considered serious or critical, and by the time of this publication, 80 patients have been supported with ECMO.

Chile is an upper middle income country with a population of 19.4 million people. Fifteen clinical centers can provide ECMO support distributed in only 6 cities; therefore, patients from remote regions requiring advanced support with ECMO, need to be transferred to these centers. In Chile, there is a central coordination system that analyzes requests for ECMO support from all hospitals in the country.
When the need for ECMO is confirmed, each patient is referred to one of the 29 available beds in ECMO centers throughout the country [15]. Currently only one center in Chile transport ECMO patients on a regular basis, although they have been done sporadically by others. In 2018, 160 ECMO supports were made in the Chile, and 25 required ECMO mobile (Chile National ECMO survey 2018, unpublished data). Figure 3 shows map providing information on the location of ECMO centers in the country.

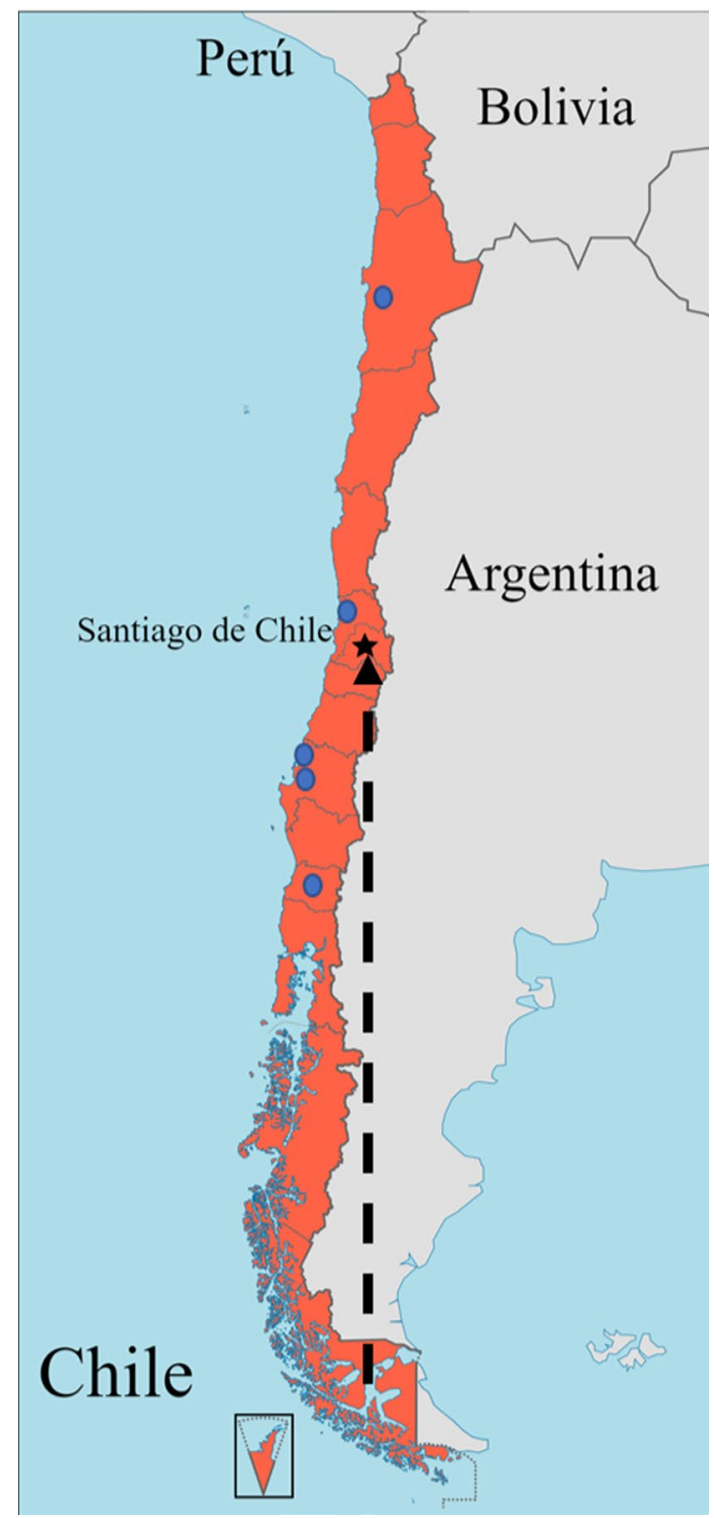

Fig. 3 Location of the 15 ECMO centers in Chile. Chile is located in southwest region of South America; its population is 17.9 million people in over $4.270 \mathrm{~km}$ from north to south and $756.945 \mathrm{~km}^{2}$ including the island territory. Fifteen clinical centers have the ability to provide ECMO support distributed in only 6 cities [10 in Santiago (black star), and 1 in Concepción, Talcahuano, Viña del Mar, Antofagasta and Temuco (blue dots)]. The arrow shows the distance traveled in mobile ECMO with the patient 
Here we report the first interhospital ECMO transport of a COVID-19 patient in our country and, to our knowledge, the first case described. The patient was too ill to undergo conventional transport, so had to be moved under ECMO support to Santiago. Patient was cannulated by ECMO mobile team at the referral center in Punta Arenas and successfully transferred to Clínica las Condes, in Santiago by airplane without any complication during transport.

An important aspect to pay attention in patients with COVID-19 is the safety of health care workers. In this case, all team members used personal protective equipment according to the procedure with generation of aerosols and the crew members used PPE to droplets and contact transmission. To minimize risk of air circuit disconnection and aerosolization during flight we decided to clamp endotracheal tube. Other ECMO teams use a strong tape to secure the connection between endotracheal tube and mechanical ventilator, but we prefer endotracheal tube clamping to avoid the risk of endotracheal tube displacement/damage at time of taping remove minimizing the risk of tube replacement need in a COVID19 patient.

All heath workers in Clínica las Condes had receive previous training in the use of PPE and the air transport company (AeroTac) has also established protocols for the transportation of COVID-19 patient. After 21 days, none of the members participating in the cannulation procedure nor in the transport was infected with SARS-Cov-2.

The experience of the rescue team can also be an important factor in the final outcomes. Clínica las Condes began the mobile ECMO program in March 2007 and until now, more than 120 patients have been transported to specialized centers. Although there is still little evidence regarding the utility of ECMO in ARDS by COVID-19, the utility in other pathologies that occur with severe ARDS has been demonstrated; waiting to gain more knowledge about this disease, patients undergoing ECMO should be managed in experienced centers. The transfer of these patients by experienced and consolidated ECMO transport teams, in addition to protocols of infection prevention and control measures could significantly influence the outcome of both the patient's disease and the safety of the health workers.

\section{Funding None.}

\section{Compliance with ethical standards}

Conflict of interest Felipe Salech is currently receiving a Grant from "FONDECYT" (Chilean government research Grant) \#11190882. The remaining authors have disclosed that they do not have any conflicts of interest.

Ethics and institutional review board A document review approval of the above case report was performed by the Review Board, as well as by the Ethics Committee of Clínica las Condes. After a detailed descriptions of the case report, a relative of the patient signed a written informed consent for publication of results.

\section{References}

1. Zhou P, Yang XL, Wang XG, Hu B, Zhang L, Zhang W, et al. A pneumonia outbreak associated with a new coronavirus of probable bat origin. Nature. 2020;579:270-3.

2. Cucinotta D, Vanelli M. WHO declares COVID-19 a pandemic. Acta Biomedica Mattioli 1885. 2020;91:157-60.

3. Wu Z, McGoogan JM. Characteristics of and important lessons from the coronavirus disease 2019 (COVID-19) outbreak in China: summary of a report of 72314 cases from the Chinese Center for Disease Control and Prevention. JAMA J Am Med Assoc. 2020;323:1239-42.

4. Brodie D, Bacchetta M. Extracorporeal membrane oxygenation for ARDS in adults. N Engl J Med. 2011;365:1905-14. Available from: https://www.ncbi.nlm.nih.gov/pubmed/22087681. Cited 21 Apr 2020.

5. Bartlett RH, Ogino MT, Brodie D, McMullan DM, Lorusso R, MacLaren G, et al. Initial ELSO guidance document. ASAIO J. 2020;8:E113-E11313.

6. Sorbello M, El-Boghdadly K, Di Giacinto I, Cataldo R, Esposito C, Falcetta S, et al. The Italian coronavirus disease 2019 outbreak: recommendations from clinical practice. Anaesthesia 2020. Available from: https://doi.wiley.com/10.1111/anae.15049. Cited 24 Apr 2020.

7. Infection prevention and control and preparedness for COVID-19 in healthcare settings—-second update [Internet]. Available from: https://www.ecdc.europa.eu/en/publications-data/infection-preve ntion-and-control-and-preparedness-covid-19-healthcare-settings. Cited 21 Apr 2020.

8. Squiccimarro E, Rociola R, Haumann RG, Grasso S, Lorusso R, Paparella D. Extracorporeal oxygenation and COVID-19 epidemic: is the membrane fail-safe to cross contamination? ASAIO J. 2020;66(8):841-843.

9. Alshahrani MS, Sindi A, Alshamsi F, Al-Omari A, El Tahan M, Alahmadi B, et al. Extracorporeal membrane oxygenation for severe Middle East respiratory syndrome coronavirus. Ann Intensive Care [Internet]. 2018;8:3. Available from: https://annal sofintensivecare.springeropen.com/articles/10.1186/s13613-0170350-x. Cited 21 Apr 2020.

10. Zeng Y, Cai Z, Xianyu Y, Yang BX, Song T, Yan Q. Prognosis when using extracorporeal membrane oxygenation (ECMO) for critically ill COVID-19 patients in China: a retrospective case series. Crit Care [Internet]. 2020;24:148. Available from: https:// ccforum.biomedcentral.com/articles/10.1186/s13054-020-2840-8. Cited 21 Apr 2020.

11. Japan ECMOnet for COVID-19. Japan ECMOnet for COVID-19: telephone consultations for cases with severe respiratory failure caused by COVID-19. J Intensive Care [Internet]. 2020;8:24. Available from: https://jintensivecare.biomedcentral.com/artic les/10.1186/s40560-020-00440-9. Cited 21 Apr 2020.

12. Henry BM, Lippi G. Poor survival with extracorporeal membrane oxygenation in acute respiratory distress syndrome (ARDS) due to coronavirus disease 2019 (COVID-19): Pooled analysis of early reports. J Crit Care. 2020;58:27-28

13. COVID-19 situation reports [Internet]. Available from: https:// www.who.int/emergencies/diseases/novel-coronavirus-2019/situa tion-reports. Cited 21 Apr 2020.

14. Extracorporeal Life Support Organization-ECMO and ECLS $>$ Registry > Full COVID-19 Registry Dashboard [Internet]. 
Available from: https://www.elso.org/Registry/FullCOVID19Regi stryDashboard.aspx. Cited 24 Apr 2020.

15. Díaz R, Antonini MV, Orrego R, Abrams D, Díaz R, Antonini $\mathrm{MV}$, et al. A propósito de la contingencia COVID-19. ECMO en el adulto: Oxigenación por membrana extracorpórea. A quién, cómo y cuándo. Rev Med Chil [Internet]. 2020;148:349-61. Available from: https://www.scielo.cl/sciel o.php?script $=$ sci_arttext $\&$ pid $=$ S0034-988720200003003 49\&lng=en\&nrm=iso\&tlng=en. Cited 26 Jul 2020.
Publisher's Note Springer Nature remains neutral with regard to jurisdictional claims in published maps and institutional affiliations. 